\title{
Alienation and Health in Adolescents: An Original Evaluation Tool
}

\author{
Gina Tomé*, Margarida Gaspar de Matos, Inês Camacho, Celeste Simões, Marta Reis, Paulo Gomes
}

FMH/University of Lisbon, ISAMB/University of Lisbon, WJCR/ISPA, Lisbon, Portugal

Email: * ginatome@sapo.pt

How to cite this paper: Tomé, G., de Matos, M.G., Camacho, I., Simões, C., Reis, M. and Gomes, P. (2018) Alienation and Health in Adolescents: An Original Evaluation Tool. Open Access Library Journal, 5: e4183. https://doi.org/10.4236/oalib.1104183

Received: November 22, 2017

Accepted: January 14, 2018

Published: January 17, 2018

Copyright $\odot 2018$ by authors and Open Access Library Inc.

This work is licensed under the Creative Commons Attribution International License (CC BY 4.0).

http://creativecommons.org/licenses/by/4.0/

(c) (i) Open Access

\begin{abstract}
The present work aims to construct and validate a tool enabling to evaluate alienation in Portuguese adolescents. Participants were a group of adolescents that participated in the Portuguese survey of the European study Health Behaviour in School-aged Children (HBSC). For this study, only adolescents from the $8^{\text {th }}$ and $10^{\text {th }}$ grades were included in the sample, comprising 3869 students. The results show a good adequacy of the confirmatory factorial analysis (CFA) model. This model revealed 3 subscales proposals-Demotivation, Isolation and Instability, and a full scale-Total Alienation. When analyzed in relation to other variables (gender, grade, wellbeing indicator and risk indicator), the alienation subscales showed an association between alienation and risk. These results are consistent with other studies about alienation which emphasizes that having good social relationships is associated with higher levels of wellbeing and quality of life and less involvement in risk behaviours by young people.
\end{abstract}

\section{Subject Areas}

Psychology, Sociology

\section{Keywords}

Adolescents, Alienation, Wellbeing, Risk

\section{Introduction}

The alienation concept has existed (implicitly or explicitly) since Marx's and Weber's [1] classical sociological works in the 19th and early 20th centuries. Since then, the concept has evolved greatly, and it is currently applied on many disciplines for specific uses. Consequently, alienation may be defined from various points of view, describing either a disconnection in a desired or expected re- 
lationship, the distrust being felt by the individual towards other people and society; or the feelings of powerlessness, senselessness, normlessness, isolation, and self-alienation being stirred in the individual due to social, institutional, or interpersonal problems.

Alienation can refer to separation, exclusion or isolation. It is associated to people with greater social difficulties or who are not involved in community activities. Sometimes it is described as the shutdown of others or of society in general, isolation, withdrawal and may affect the perception of health in young people [2].

According to the psychological theory of alienation, which is in line with the existentialist theory of psychological wellbeing, the need to belong is one of the strongest human needs and thwarting the need to belong and find meaning can have devastating consequences for wellbeing itself [3]. The alienated person is socially less effective and does not strongly connect to the goals part of the society to which he or she should belong [2].

Barber (2014), considers that implied in the foregoing definitions are two psychological properties worth noting because they apply to students. The first is that alienation occurs in a social setting or context toward which an individual feels negative sentiment (e.g. disappointment, anger). This sentiment may be targeted at a specificity, a process, or even the broader milieu or context in which the estrangement occurs. The second property is that of perceived constraint. Part of a student's feelings of alienation, including the intensity of these feelings, is a product of the extent to which they feel "caught" or "trapped" in an unsatisfying situation [4].

Individuals in the role of "student" may become alienated due, for instance, to negative experiences with teachers or colleagues, by the requirements of a course, or by failed attempts to assimilate into various social groups. Feelings of alienation in education contexts may emerge, in part or in whole, because of such processes. These feelings, since they become generalized, constitute the subjective psychological state of alienation [5].

Interpersonal relationships have great importance during adolescence, especially for psychological wellbeing. The sensation of wellbeing during adolescence can depend on the integration and acceptance of the peer group [6]. Adolescents' mental health may be affected by difficulties in maintaining social relationships with peers, through the absence of sense of belonging, rejection by peers, or a break in social relations [7].

Therefore, alienation can be considered a risk factor (feelings of "not belonging", difficulties in interpersonal relationships, social exclusion) during adolescence, since it appears related to several physical and psychological health problems [8]. In school, adolescents with feelings of "not belonging" to a peer group are those with fewer friends, a smaller social network and with lower self-esteem. These feelings can promote the development of symptoms of depression and other psychological symptoms [2]. Social exclusion is so aversive that it causes 
broad cognitive and behavioral changes in the regulation of an individual's belonging status [9].

The results found by Tomé, Matos, Camacho, Simões, Reis, Ramiro and Gomes (2016) indicated that adolescents with higher levels of social alienation scored higher in health risks behaviours ("drunkenness", "use of tobacco", "fights" and "sadness/depression") than adolescents with low levels of social alienation. There was a positive association between social isolation and adolescent's health risk behaviours, such as engaging in a bullying behaviour.

Other studies have provided consistent evidence that school alienation is due to children lacking a feeling of subjective relevance and bonding with school and the influence of parenting. Kocayoruk and Simsek (2015) found that secure attachment to parents was negatively associated with feelings of school alienation, and adjustment and self-esteem were crucial mediators between attachment to parents and school alienation [10].

The phenomena of alienation are slow and systematic at the affective level. It is important to identify and solve the individual's problem of alienation because it may lead to other serious problems such as substance abuse, alcoholism and other severe emotional disorders, and suicide [1].

Thus, the ultimate challenge for him now is to find his place in society. It has often been observed that an alienated individual lacks the necessary competencies to function effectively in various spheres of life including home, school, community, workplace and society at large. Alienation is an experience which has become more and more a fact of life in these days of modernization. Probably adolescents feel this much more intensely than the older people or children [11].

David and Nita (2014) consider that designing small intervention programs like a socialization week or tutoring activities reduces alienation and helps freshmen continue attending school. Intervention programs with suitable activities will introduce students to the habits of university life and allow them to familiarize themselves with the environment and with the obligations and the rights that they have to be aware of. Their sense of control is likely to increase and with it the sense of being alone and lacking understanding of life matters decreases [12].

Recently, a framework for understanding behaviour was proposed and designed as the Behaviour Change Wheel Model (BCW). The BCW model was developed based on theoretical and evidenced-based instruments that allow the design and selection of interventions and policies, in agreement with 1) the analysis of behaviour nature; 2) the mechanisms for behaviour change; 3 ) the interventions and policies needed to change those mechanisms. In addition, this model grew from the need to identify effective interventions. For that purpose, it is crucial to have a characterization system that can match those interventions with the specific behaviour to be achieved, the target population and the context where it is going to be conducted. Authors state that this characterization system 
should be applied to any interventions and neither comprising too broad or too specific categories. Thus, the categories must be coherent and in relationship with the specific mechanisms for behavioural change. This system is the COM-B system. The COM-B system suggests that for behavioural change to happen, at least three components are needed:

1) Capacity, i.e., physical and psychologic skills for behaviour change, mainly knowledge and competence;

2) Motivation, i.e., the intention to act, which include emotional and impulsive processes, as well as a reflexive process of decision making;

3) Opportunity, i.e., that no external factors interfere with the behaviour action. In this system, there is a dual interaction between the three factors and the behaviour and a specific intervention can change one or more components of the system itself. The BCW model reinforces the context (corresponding to the component Opportunity) as a key factor for the design and implementation of effective interventions. Therefore, behaviour can be only understood in the relationship with the context and both are the starting point for planning interventions [13]. So, if these components are not present, the behaviour may not change and involvement in risk behaviours for adolescents mental health may increase.

Thus, it is possible to verify that alienation is a relevant concept in health-related research among adolescents. The measurement of alienation is, however, challenging and varies in several ways.

Rayce, Holstein and Kreineiner (2009) analyzed the association between alienation towards oneself, towards those closest to oneself, and the outcome symptom load and found a graded and significant association between alienation and high symptom load. For this analysis, the authors constructed and validated an index of alienation, with data stems from the Danish contribution to the crossnational study Health and Behaviour in School-aged Children (HBSC).

Tomé, Matos, Camacho, Simões, Gomes and Almeida (2015), in a study which aimed to construct and validate a tool to evaluate alienation in Portuguese adolescents in the four above-mentioned dimensions, found that their version of alienation assessment demonstrated differences among adolescents in terms of gender, grade and socioeconomic status (SES) [14]. This is the only tool to evaluate alienation in Portuguese adolescents. This tool was built from the adaptation of existing questions in the Portuguese study HBSC.

Based on the specific needs of adolescents in school context, this study aimed to construct and validate an original tool to evaluate alienation, that has not arisen from the adaptation of existing issues and not only to estimate alienation and its components in Portuguese adolescents, but also to identify associations regarding other demographic variables. The tool may help identify and prevent risk behaviors associated with difficulties in interpersonal relationships that interfere with the well-being of young people, as can be seen in the literature review. 


\section{Method}

\subsection{Procedures}

This survey is part of the Health Behaviour in School-aged Children (HBSC) study (Currie et al., 2004; Currie et al., 2012; Matos et al., 2006; Matos et al., 2012). The Health Behaviour in School-aged Children (HBSC) is a collaborative WHO study, undertaken in 44 countries with the aim to study school-aged behaviour regarding health and risk behaviors in adolescence. Portugal is part of this group of countries since 1996. The HBSC is a school-based survey of adolescents' health behaviours, carried out every 4 years. Collected data is used at a national and international level, using an internationally standardized methodological protocol [15] to gain a new vision into young people's health and well-being, so as to understand the social and psychological determinants of health and to incorporate policies to improve young people's lives.

A questionnaire with open-ended and closed-ended questions was administered in the classroom with the assistance of the informatics teacher, using an online procedure, and took an average of 50 minutes (a regular class length) to fill in. Researchers were available to answer the students' questions. This study was approved by the scientific committee, the ethical national committee (Ethics Committee for Health of the São João Hospital Center/Faculty of Medicine of the University of Porto) and the Portuguese data protection authority (National Data Protection Commission). The request of consent for the adolescents' parents was sent to all adolescents and participated only those that were authorized by their responsible.

The alienation tool validate in this study was constructed following the adaptation of some alienation questions used in the HBSC 2010 study (see Tomé et al. 2015). The questions were structured and a pilot study was carried out with some adolescents. Young people were asked to comment the questions, based on the definition of alienation presented to them. Then, the responses and comments of the young people were analysed and was created the tool with the 10 items. After the exploratory factorial analysis, the factors suggested were analysed and according to the literature review and comments of the young, the factors were named.

\subsection{Participants}

The 2014 study provided national representative data of 6026 Portuguese adolescents, randomly chosen from those attending $6^{\text {th }}$ grade, $8^{\text {th }}$ grade (middle school) and $10^{\text {th }}$ grade (high school) during the 2013/2014 academic year. The sample included $52.3 \%$ of girls and $47.7 \%$ of males, whose mean age was 14.0 years old (standard deviation 1.7). The majority of adolescents were Portuguese (94.7\%), $35.8 \%$ attended the $6^{\text {th }}$ grade, $39.1 \%$ attended the $8^{\text {th }}$ grade and $25.1 \%$ attended the $10^{\text {th }}$ grade. This study used a subset of $8^{\text {th }}(\mathrm{n}=2358)$ and $10^{\text {th }}$ graders $(n=1511)$ to represent middle school and high school educational stages. The majority was female (middle school, 51.1\%; high school, 56.3\%), Portuguese 
(95.2\% and $94.2 \%$, respectively) and their mean ages were 13.9 and 15.9 years old, respectively (standard deviation 0.7 for both). They were randomly selected from 36 national vertical clusters of schools, in a total of 473 classes, in a national sample geographically stratified by Education Regional Divisions in Portugal. The overall procedure, has been described elsewhere (Currie et al., 2004; Matos et al., 2012); in brief, this study has the approval of a scientific committee, an ethical national committee and the national commission for data protection and followed strictly all the guidelines for protection of human rights; adolescents' participation in the survey and completion of the questionnaires was voluntary and anonymous. The sample was nationally representative of the respective grade levels. The response rate was $79 \%$.

\subsection{Measures and Variables}

The data collection was conducted through the HBSC 2014 Questionnaire (Currie et al., 2004). This questionnaire provides information about demographic data, well-being indicators (quality of life related with health, happiness and satisfaction with life) and about the relationship with peers and family, among other variables (Currie, Samdal, Boyce \& Smith, 2001; Matos et al., 2006).

\subsection{Statistical Analysis}

Data was analysed with the statistics program SPSS 22. Descriptive analysis followed by bivariate analysis was carried out.

With the aims to construct and validate a tool to evaluate alienation in Portuguese adolescents, anexploratory and a confirmatory factor analysis (CFA) was conducted with the EQS 6.2 for windows. Multiple fit indexes were used to evaluate goodness of fit of models tested in the study: chi-square statistics $\left(\chi^{2}\right)$, comparative fit index (CFI), non-normed fit index (NNFI), root mean square error of approximation (RMSEA), and standardized root mean squared residual (SRMR).

To analyze the differences between the factors found and some variables was used the ANOVA test.

\section{Results}

The present study used issues specifically created to evaluate alienation. These questions showed good internal consistency $(\alpha=0.50)$. The internal consistency of each of the three subscales was also good: Demotivation $\alpha=0.82$, Isolation, $\alpha$ $=0.87$ and Instability $\alpha=0.71$ (see Table 3, which shows internal consistency of the scales). In addition to the subscales, other variables were measured. The wellbeing Indicator was measured with the items assessing happiness and the items assessing communication with mother and father. The happiness and communication items showed questionable internal consistency, $\alpha=0.62$. The Risk Indicator was measured with the items assessing "drunkenness", "use of tobacco", fights, "sadness/depression" and "so sad that almost could not stand", 
and it showed poor internal consistency, $\alpha=57$.

Initially an exploratory factorial analysis was carried out. Exploratory factorial analysis has been one of the statistical procedures most used in the development, evaluation and adjustment of psychological instruments. In analyzing the structure of the interrelationships of a number of variables observed, the EFA defines the factor(s) that best explains its covariance. It was verified the existence of three factors (see Table 1, which shows the items of the exploratory factor analysis). Confirmatory factor analysis confirmed the existence of three factors (Demotivation, Isolation and Instability).

Table 2 shows that the adjustment index of the CFA was acceptable and the model shows a good adequacy.

Alternative fit indexes such as the comparative fit index (CFI), non-normed fit index (NNFI), root mean square error of approximation (RMSEA), standardized root mean squared residual (SRMR) are presented. The procedures used to determine factorial invariance included: verification of configure invariance, in which the equivalence of the specified structure of factor loading is tested (unconstrained model); Simulation studies show that the difference in CFI between the model with and without restrictions is among the most adequate measures to assume factorial invariance (Cheung \& Rensvold, 2000). So, the standardized

Table 1. Exploratory factor analysis.

\begin{tabular}{|c|c|c|c|}
\hline \multirow[t]{2}{*}{ Factor Analysis } & \multicolumn{3}{|c|}{ Factors } \\
\hline & Demotivation & Isolation & Instability \\
\hline In general, when I try hard I get good results. & 0.696 & & \\
\hline Usually, when I have suggestions, people hear me. & 0.716 & & \\
\hline $\begin{array}{l}\text { On a daily basis I try to develop my interests } \\
\text { and talents. }\end{array}$ & 0.751 & & \\
\hline I think one day many of my dreams will come true. & 0.783 & & \\
\hline $\begin{array}{l}\text { Many of the tasks that I have to do, help me to } \\
\text { develop my skills and my interests. }\end{array}$ & 0.761 & & \\
\hline $\begin{array}{l}\text { I feel lonely very often, even when I am with other } \\
\text { people. }\end{array}$ & & 0.913 & \\
\hline I feel isolated and misunderstood very often. & & 0.92 & \\
\hline $\begin{array}{l}\text { It's hard to know what one can count on, } \\
\text { because things are changing all the time. }\end{array}$ & & & 0.851 \\
\hline $\begin{array}{l}\text { People thoughts change so quickly that nothing } \\
\text { can be taken for granted. }\end{array}$ & & & 0.822 \\
\hline Sometimes I wonder if it's worth that I make an effort. & & & 0.453 \\
\hline Explained variance & 37.99 & 19.59 & 9.24 \\
\hline
\end{tabular}

Table 2. Adjustment index.

\begin{tabular}{cccccc}
\hline & $\chi^{2}(\mathrm{df})$ & CFI & NNFI & RMSEA (90\% I.C.) & SRMR \\
\hline Step 1 & $383.1168(32)$ & 0.96 & 0.95 & $0.060(0.054-0.065)$ & 0.056 \\
Step 2 & $316.1474(29)$ & 0.97 & 0.95 & $0.057(0.051-0.063)$ & 0.054 \\
\hline
\end{tabular}


solution in the CFA model showed that, in general, the independent factor had a good impact on the dependent factors, ranging from $\beta=-0.59$ and $\beta=1$ (Figure 1, which shows Confirmatory Factor Analysis).

The following three factors were identified: Demotivation, Isolation and Instability. There was good internal consistency for all three factors, with values ranging between $\alpha=0.71$ and $\alpha=0.87$ (see Table 3, which shows internal consistency of the scales).

The explained variance factors, as well as the residual, for the confirmatory factor analysis model are presented in Table 4 . As shown, these values are also appropriate and range from $R^{2}=0.16$ and $R^{2}=1$.

Correlation analysis was conducted between the variables Demotivation, Isolation and Instability, Total Alienation, Wellbeing Indicator and Risk Indicator.

The strongest correlations were between Demotivation and Total Alienation (0.531) and Instability and Total Alienation (0.376), and negative correlations between Demotivation and Isolation $(-0.099)$, Instability $(-0.460)$ and Wellbeing Indicator $(-0.190)$ (see Table 5, which shows the correlations between the

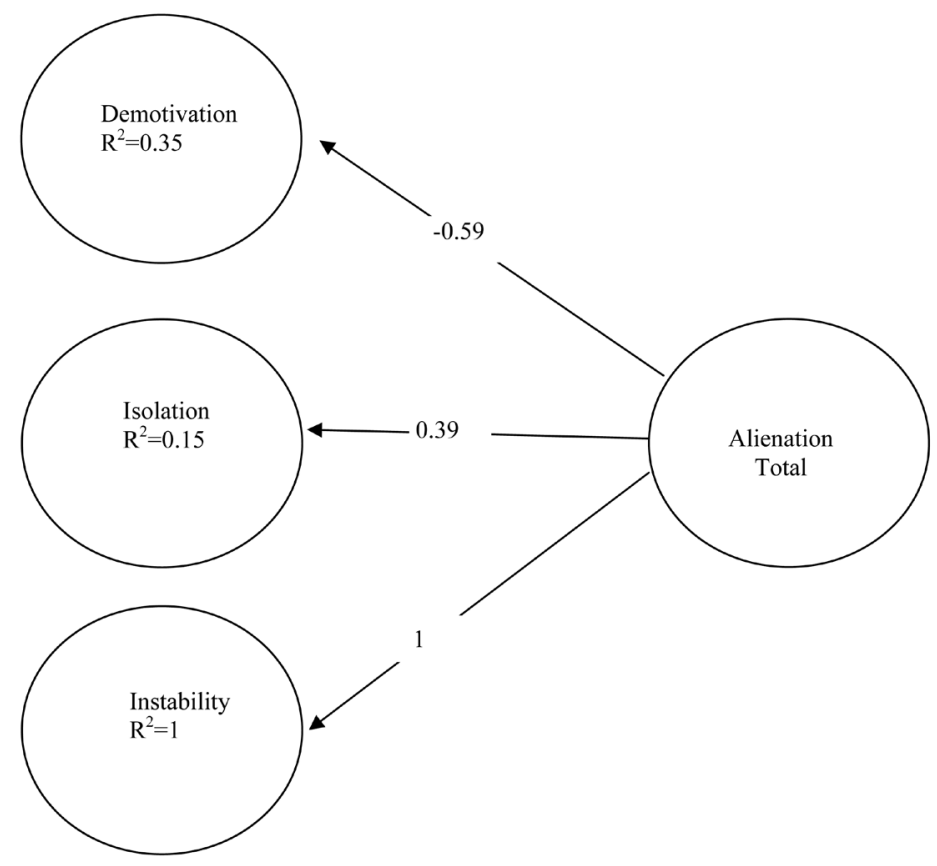

Figure 1. Confirmatory factor analysis.

Table 3. Internal consistency of the scales.

\begin{tabular}{cccccc}
\hline Factors & Items & $\mathbf{N}$ & $\boldsymbol{M}$ & $\boldsymbol{S D}$ & Cronbach \\
\hline Total & 10 & 3066 & 17.9 & 3.6 & 0.50 \\
1 (Demotivation) & 5 & 3166 & 8.3 & 2.1 & 0.82 \\
2 (Isolation) & 2 & 3216 & 4.4 & 1.3 & 0.87 \\
3 (Instability) & 3 & 3185 & 5.3 & 1.9 & 0.71 \\
\hline
\end{tabular}


Table 4. Explained variance $\left(\mathrm{R}^{2}\right)$ and residual error (Disturbance).

\begin{tabular}{ccc}
\hline Factor & $\mathbf{R}^{2}$ & Disturbance \\
\hline 1 (Demotivation) & 0.35 & 0.81 \\
2 (Isolation) & 0.16 & 0.92 \\
3 (Instability) & 1 & 0 \\
\hline
\end{tabular}

Table 5. Correlations.

\begin{tabular}{ccccccc}
\hline & Demotivation & Isolation & Instability & $\begin{array}{c}\text { Total } \\
\text { Alienation }\end{array}$ & $\begin{array}{c}\text { Wellbeing } \\
\text { Indicator }\end{array}$ & Risk Indicator \\
\hline Demotivation & - & $-0.099^{* *}$ & $-0.460^{* *}$ & $0.531^{\star *}$ & $-0.190^{* *}$ & $0.158^{* *}$ \\
Isolation & - & - & $0.406^{* *}$ & $0.671^{\star *}$ & $-0.188^{* *}$ & $0.278^{* *}$ \\
Instability & - & - & - & $0.376^{\star *}$ & $-0.061^{\star *}$ & $0.115^{* *}$ \\
Total Alienation & - & - & - & - & $-0.291^{* *}$ & $0.336^{* *}$ \\
Wellbeing & - & - & - & - & - & $-0.341^{* *}$ \\
Indicator & - & - & - & - & & \\
\hline
\end{tabular}

${ }^{* *} \mathrm{p}<0.01$.

subscales).

After these analyses, the differences between the alienation subscales for gender, grade, Wellbeing Indicator and Risk Indicator were observed. Regarding the mean differences using the ANOVA test, the results showed that girls had higher means for the following subscales: Alienation Total $(M=18.5, S D=2.6)$ $(F(1,3064)=14.529, p \leq 0.001)$ and Demotivation $(M=8.3, S D=2)(F(1$, $3164)=34.424, p \leq 0.001)$. The results for the Isolation and Instability subscales were not statistically significant (see Table 6 , which shows the comparisons between alienation subscales according to gender, grade, wellbeing and risk).

Regarding the variable grade, the adolescents from the $8^{\text {th }}$ grade had higher means for the following subscales: Isolation $(M=3.6, S D=1.4)(F(1,3164)=$ $11.500, p \leq 0.01)$ and Uncertainty $(M=6.7, S D=1.4)(F(1,3183)=5.790, p \leq$ $0.05)$. The adolescents from the $10^{\text {th }}$ grade had higher means for the Demotivation $(M=8.2, S D=2)(F(1,3183)=8.160, p \leq 0.001$ (see Table 6 , which shows the comparisons between alienation subscales according to gender, grade, wellbeing and risk).

For Wellbeing Indicator, the adolescents with low wellbeing have higher means for all Alienation subscales (see Table 6, which shows the comparisons between alienation subscales according to gender, grade, wellbeing and risk).

Finally, for Risk Indicator, the adolescents with high risk have higher means for all Alienation, as shown in Table 6 (which shows the comparisons between alienation subscales according to gender, grade, wellbeing and risk).

\section{Discussion}

Alienation can be considered a risk factor during adolescence, since it appears related to several physical and psychological health problems [8]. Feelings of 
Table 6. Comparisons between alienation subscales according to gender, grade, Wellbeing and Risk (ANOVA).

\begin{tabular}{|c|c|c|c|c|c|c|c|c|}
\hline \multirow[t]{2}{*}{ Gender } & \multicolumn{3}{|c|}{ Boy } & \multicolumn{3}{|c|}{ Girl } & \multirow[b]{2}{*}{$F$} & \multirow[b]{2}{*}{$p$} \\
\hline & $N$ & $M$ & $S D$ & $N$ & $M$ & $S D$ & & \\
\hline Alienation Total & 1419 & 18.1 & 2.4 & 1647 & 18.5 & 2.6 & 14.529 & 0.000 \\
\hline Demotivation & 1457 & 7.9 & 2.2 & 1709 & 8.3 & 2 & 34.424 & 0.000 \\
\hline Isolation & 1481 & 3.5 & 1.4 & 1735 & 3.5 & 1.3 & 0.047 & 0.827 \\
\hline Instability & 1474 & 6.7 & 1.4 & 1711 & 6.6 & 1.3 & 2.395 & 0.122 \\
\hline \multirow[t]{2}{*}{ Grade } & \multicolumn{3}{|c|}{8 th grade } & \multicolumn{3}{|c|}{ 10th grade } & & \\
\hline & $N$ & $M$ & $S D$ & $N$ & $M$ & $S D$ & $F$ & $p$ \\
\hline Alienation Total & 1770 & 18.3 & 2.5 & 1296 & 18.3 & 2.7 & 0.403 & 0.526 \\
\hline Demotivation & 1842 & 8 & 2.2 & 1324 & 8.2 & 2 & 8.160 & 0.004 \\
\hline Isolation & 1875 & 3.6 & 1.4 & 1341 & 3.4 & 1.3 & 11.500 & 0.001 \\
\hline Instability & 1858 & 6.7 & 1.4 & 1327 & 6.5 & 1.3 & 5.790 & 0.016 \\
\hline \multirow[t]{2}{*}{ Wellbeing Indicator } & \multicolumn{3}{|c|}{ High } & \multicolumn{3}{|c|}{ Low } & & \\
\hline & $N$ & $M$ & $S D$ & $N$ & $M$ & $S D$ & $F$ & $p$ \\
\hline Alienation Total & 1383 & 17.7 & 2.5 & 1317 & 18.8 & 2.4 & 145.248 & 0.000 \\
\hline Demotivation & 1422 & 7.8 & 2.2 & 1365 & 8.4 & 2 & 66.164 & 0.000 \\
\hline Isolation & 1448 & 3.3 & 1.4 & 1380 & 3.7 & 1.3 & 57.020 & 0.000 \\
\hline Instability & 1435 & 6.6 & 1.4 & 1363 & 6.7 & 1.3 & 4.449 & 0.035 \\
\hline \multirow[t]{2}{*}{ Risk Indicator } & \multicolumn{3}{|c|}{ High } & \multicolumn{3}{|c|}{ Low } & & \\
\hline & $N$ & $M$ & $S D$ & $N$ & $M$ & $S D$ & $F$ & $p$ \\
\hline Alienation Total & 1277 & 19.2 & 2.3 & 1760 & 17.7 & 2.5 & 279.145 & 0.000 \\
\hline Demotivation & 1324 & 8.4 & 2.1 & 1811 & 7.9 & 2.1 & 39.354 & 0.000 \\
\hline Isolation & 1351 & 3.9 & 1.3 & 1835 & 3.2 & 1.3 & 223.206 & 0.000 \\
\hline Instability & 1335 & 6.8 & 1.3 & 1820 & 6.5 & 1.4 & 42.792 & 0.000 \\
\hline
\end{tabular}

alienation are characterized by an individuals' belief that he/she is different from others. In this state, the individual experiences low self-esteem and aspires to become another person, which can lead to psychological problems. The phenomena of alienation are slow and systematic at the affective level. It is important to identify and solve the individual's problem of alienation because it may lead to other serious problems such as substance abuse, alcoholism and other severe emotional disorders, and suicide [1].

Tomé et al. (2015), constructed and validated a tool to evaluate alienation in adolescents. This tool was an adaptation of the existing questions in the Portuguese study HBSC. The authors found that their version of alienation assessment demonstrated differences among adolescents in terms of gender, grade and socioeconomic status (SES) [14]. This was the only tool available to evaluate alienation in Portuguese adolescents. These results show the need to continue to 
evaluate and identify the feelings of alienation among adolescents.

Considering this gap, this study aimed to construct and validate an original tool to evaluate alienation, that has not arisen from the adaptation of existing issues. In order to distinguish the tools, this tool was named "Alienation Scale-Tomé and Matos". The results for the "Alienation Scale-Tomé and Matos" showed the adjustment index of the CFA model and its good adequacy. The model presented 3 scale proposals-Demotivation, Isolation and Instability, and a full scale-Alienation Total.

The good fit of the data will allow the use of the scale in the analysis of alienation among Portuguese adolescents, enabling the prevention and mediation of a problem that can negatively influence youth. The present version of the alienation tool also demonstrated differences among adolescents in terms of gender, grade Wellbeing Indicator, and Risk Indicator. Several studies showed the differences between boys and girls regarding their friendships and interpersonal relationships [16]-[21].

As for gender, girls revealed higher feelings of alienation, revealing the need for different gender interventions, with greater attention to the risk presented by girls regarding social alienation. These results were similar to those presented by Tomé et al. (2016), who verified that boys were more influenced by satisfaction with life and the relationship they had with their family. Girls, on the other hand, presented a stronger association with feelings of alienation when bullying victims or harming others. The same happened with feelings of powerlessness, where the bullying and drunkenness variables affected girls more than boys. These differences between genders confirm the need for a differentiated intervention for boys and girls, in order to produce positive results [20].

The results make visible the association between the risk and the lowest wellbeing and alienation. This association between alienation and risk was found in previous studies. Tomé et al. (2016; 2017), found in their study an association between alienation and risk. It appears that adolescents with increased social isolation and normlessness have more involvement in risk behaviors [20] [21]. They noted that the feeling of unsatisfaction with life seemed to have a lot of influence to feelings of powerlessness, while the association between normlessness and the poorest relationship with family was equally high. Being satisfied with life and having a good relationship with family were important assets in adolescent's mental health.

Social relationships are thought to affect health via multiple pathways, including: direct impacts on negative and positive affect; changes in perceptions and responses to stressors; impacts on stress-sensitive biological systems; and changes in health behaviours. The mental health of adolescents may be affected by difficulties in maintaining social relationships with peers, through the absence of sense of belonging, rejection by peers, or a break in social relations.

In the present study, the results also indicate some health risks in adolescents with higher levels of alienation. Similarly to previous studies, there was a positive 
association between adolescents' social isolation and adolescents' health risk behaviours [14] [19] [20] [21]. Other results highlight the need for interventions focused on assisting young people in maintaining relationships and positive assets. Having a good relationship with friends are important assets in adolescent mental health. When these are negative they lead to feelings that may deteriorate wellbeing and mental health.

According to Michie, Van Stralen, and West (2011), behavior change will not happen if interventions do not take into account: Capacity, Motivation, and Opportunity. The validate tool in this study reveals three factors that seem to be a consequence of failure in the process identified by the authors. So, it seems important to define interventions taking into account the factors identified by Michie and collaborators, in order to prevent social alienation among young people, especially the Demotivation, Isolation and Instability, is necessary to work social skills of adolescents promoting mental health and positive relationships and consequently prevent feelings of alienation.

\section{Conclusions}

Alienation can be considered as a risk factor during adolescence. Feelings of alienation are characterized by an individuals' belief that he/she is different from others. In this state the individual experiences low self-esteem and aspires to become another person, which can lead to psychological problems. During adolescence, individuals have a strong desire for peer relationships and to be accepted by peers.

In Portugal there is no valid instrument for assessing alienation among adolescents. So it is very important to build and validate a tool to assess alienation. The good fit of the data in this study will allow the use of the scale in the analysis of alienation among Portuguese adolescents, enabling the prevention and mediation of a problem that can negatively influence youth.

\section{References}

[1] Arora, P.S. and Singh, G. (2014) Self-Efficacy and Emotional Intelligence as Redictors of Alienation among Graduates. International Journal of Innovative Research and Development, 3, 258-262.

[2] Safipour, J., et al. (2011) The Mediating Role of Alienation in Self-Reported Health among Swedish Adolescents. Vulnerable Groups \& Inclusion, 2, 5805. https://doi.org/10.3402/vgi.v2i0.5805

[3] Ifeagwazi, C., Chukwuorji, J. and Zacchaeus, E. (2014) Alienation and Psychological Wellbeing: Moderation by Resilience. Social Indicators Research, 1-20.

[4] Barber, C.E. (2014) The Disillusionment of Students Denied Admission to a Preferred Major Viewed from the Perspective of a Psychological Theory of Alienation. College Student Journal, 154-165.

[5] Barnhardt, B. and Ginns, P. (2014) An Alienation-Based Framework for Student Experience in Higher Education. The International Journal of Higher Education Research, 68, 789.

[6] Corsano, P., Majorano, M. and Champretavy, L. (2006) Psychological Well-Being in 
Adolescence: The Contribution of interpersonal Relations and Experience of Being Alone. Adolescence, 41, 341-353.

[7] Bakker, M.P., et al. (2010) Peer Stressors and Gender Differences in Adolescents' Mental Health: The TRAILS Study. Journal of Adolescent Health, 46, 444-450. https://doi.org/10.1016/j.jadohealth.2009.10.002

[8] Rayce, S.L., Holstein, B.E. and Kreiner, S. (2009) Aspects of Alienation and Symptom Load among Adolescents. European Journal of Public Health, 19, 79-84. https://doi.org/10.1093/eurpub/ckn105

[9] Kawamoto, T., Nittono, H. and Ura, M. (2014) Social Exclusion Induces Early-Stage Perceptual and Behavioral Changes in Response to Social Cues. Society for Neuroscience, 9, 174-185. https://doi.org/10.1080/17470919.2014.883325

[10] Kocayoruk, E. and Simsek, O.F. (2015) Parental Attachment and Adolescents' Perception of School Alienation: The Mediation Role of Self-Esteem and Adjustment. The Journal of Psychology, 150, 405-421. https://doi.org/10.1080/00223980.2015.1060185

[11] Kaur, J. and Singh, G. (2015) Alienation among Urban Adolescents in Relation to Emotional Intelligence. International Journal of Allied Practice, Research and Review, 7, 32-36.

[12] David, L.T. and Nită, G.L. (2014) Adjustment to First Year of College-Relations among Self-Perception, Trust, Mastery and Alienation. Procedia-Social and Behavioral Sciences, 127, 139-143. https://doi.org/10.1016/j.sbspro.2014.03.228

[13] Michie, S., van Stralen, M.M. and West, R. (2011) The Behaviour Change Wheel: A New Method for Characterising and Designing Behaviour Change Interventions. Implementation Science, 6, 42-42. https://doi.org/10.1186/1748-5908-6-42

[14] Tomé, G., et al. (2015) Strangers, Powerless and Hopeless in Their Own Town: Alienation among Adolescents in Times of Recession, an Assessment Tool. British Journal of Education, Society \& Behavioural Science, 8, 247-255. https://doi.org/10.9734/BJESBS/2015/17546

[15] Roberts, C., et al. (2009) The Health Behaviour in School-Aged Children (HBSC) Study: Methodological Developments and Current Tensions. International Journal of Public Health, 54, 140-150. https://doi.org/10.1007/s00038-009-5405-9

[16] Tomé, G., et al. (2012) How Can Peer Group Influence the Behavior of Adolescents: Explanatory Model. Global Journal of Health Science, 4, 26-35. https://doi.org/10.5539/gihs.v4n2p26

[17] Tomé, G., et al. (2013) The Lack of Friends amongst Adolescents and Well-Being. International Journal of Science, 2, 43-51.

[18] Molcho, M., et al. (2009) Cross-National Time Trends in Bullying Behaviour 1994-2006: Findings from Europe and North America. International Journal of Public Health, 54, 225-234. https://doi.org/10.1007/s00038-009-5414-8

[19] Tomé, G., et al. (2014) Friendships Quality and Classmates Support: How to Influence the Well-Beingof Adolescents. Higher Education of Social Science, 7, 149-160.

[20] Tomé, G., et al. (2016) Alienation and Well-Being in Adolescents. Social Isolation Is a Risk? IJSRM Human, 5, 1-14.

[21] Tomé, G., et al. (2017) Alienation Impact on Portuguese Adolescents' Health. Europe's Journal of Psychology. 